\title{
Dietary Conjugated Linoleic Acid Reduces Lipid Peroxidation by Increasing Oxidative Stability in Rats
}

\author{
Hye-Kyeong Kim, Sung-Ran Kim, Ji-Yoon Ahn, Il-Jin Cho, Chil-Suk Yoon ${ }^{1}$ and Tae-Youl HA* \\ Food Function Research Division, Korea Food Research Institute, Seongnam 463-746, Korea \\ ${ }^{1}$ Livemax Co. Ltd., Seongnam 463-746, Korea
}

(Received October 15, 2003)

\begin{abstract}
Summary The antioxidative effect of conjugated linoleic acid (CLA) was examined by determining lipid peroxidation and antioxidative enzyme activities. Male Sprague-Dawley rats were fed one of the experimental diets-normal diet, vitamin E-deficient control diet, 0.5\% CLA vitamin E-deficient diet, or 1.5\% CLA vitamin E-deficient diet for $5 \mathrm{wk}$. Hepatic thiobarbituric acid reactive substances (TBARS) were increased in the vitamin E-deficient control group, but they were was significantly lowered in the CLA groups. Similarly, hepatic glutathione peroxidase activity was increased in the vitamin E-deficient diet and reduced by CLA supplementation. In addition, CLA caused a significant decrease in superoxide dismutase activity while having no effect on catalase activity. Analyses of the fatty acid composition revealed that dietary CLA was incorporated into hepatic microsomal membrane dosedependently. Compared to the vitamin E-deficient control, CLA resulted in significantly higher saturated and monounsaturated fatty acids (palmitic and oleic acids) while lowering levels of oxidation-susceptible polyunsaturated fatty acids (linoleic, linolenic, and arachidonic acids) in both plasma and hepatic membrane. The concentrations of plasma cholesterol and triacylglycerol (TG) were lower in the 1.5\% CLA group than in other groups. These results suggest that dietary CLA has antiatherosclerotic and antioxidant activity by increasing oxidative stability in plasma and hepatic membrane in the vitamin E-deficient rats.
\end{abstract}

Key Words conjugated linoleic acid, lipid peroxidation, antioxidative enzyme, fatty acid composition, vitamin E-deficient diet

Conjugated linoleic acid (CLA) is a collective term for the positional and geometric isomers of linoleic acid. Much attention has been given to CLA because it has diverse physiological functions such as anticarcinogenic, antiatherosclerotic, immunomodulatory activities and altering body composition (1-4). However, the mechanism of their biological actions is still poorly understood.

It has been accepted that free radicals and radicalmediated oxidation play a role in many pathological processes, such as carcinogenesis and atherosclerosis. Thus, considerable effort has been invested in the search for natural and synthetic antioxidants that may help prevent or treat these diseases. CLA was identified to prevent cancer and atherosclerosis in a number of model systems, and antioxidant activity has been investigated by several research groups since it was considered as a possible explanation for their biological activities $(5,6)$. However, the previous studies have reported conflicting results of the antioxidant properties. Ha et al. reported that CLA acted as an antioxidant more effective than $\alpha$-tocopherol and comparable to butylated hydroxytoluene (BHT) in vitro (7). This observation was supported by Ip et al. (6). They found that CLA

*To whom correspondence should be addressed.

E-mail: tyhap@kfri.re.kr supplementation inhibited lipid peroxidation in mammary gland of rats. On the contrary, van den Berg et al. reported that CLA did not act as an effective radical scavenger and metal chelator, using a phosphatidylcholine liposome model system (8). This result indicated that CLA acted similar to other polyunsaturated fatty acids under oxidative stress. Thus, it appears that the experimental evidence is insufficient to substantiate CLA as an antioxidant.

It was reported that dietary CLA can reduce atherogenic risk by decreasing plasma triacylglycerol, totaland LDL-cholesterol levels $(2,5)$. The plasma triacylglycerol and lipoproteins are synthesized mainly in the liver. Microsomes contain fatty acid desaturases and the enzymes catalyzing the synthesis of phosphatidic acid, a key intermediate in both triacylglycerol and phospholipids synthesis. Membrane fatty acids serve as modulators of the biological processes such as eicosanoid production and activation of membrane-bound enzymes $(9,10)$. Therefore, study of the fatty acid composition of the hepatic membrane is thought to be important for understanding the effect of dietary CLA on plasma lipids. Dietary CLA could also result in changes in lipid peroxidation by altering fatty acid composition. However, studies have not been performed to determine whether the effect of CLA on plasma lipid and lipid peroxidation is mediated through alteration in the fatty 
Table 1. Composition of experimental diets.

$(\mathrm{g} / \mathrm{kg}$ diet $)$

\begin{tabular}{|c|c|c|c|c|}
\hline & Normal & Control & $0.5 \%$ CLA & $1.5 \%$ CLA \\
\hline Casein $^{1}$ & 200 & 200 & 200 & 200 \\
\hline Corn oil ${ }^{1}$ & 70 & 70 & 65 & 55 \\
\hline Mineral mixture ${ }^{2}$ & 35 & 35 & 35 & 35 \\
\hline Vitamin mixture $\mathrm{e}^{1,2}$ & 10 & 10 & 10 & 10 \\
\hline Choline chloride & 2 & 2 & 2 & 2 \\
\hline DL-Methionine & 3 & 3 & 3 & 3 \\
\hline Cellulose & 50 & 50 & 50 & 50 \\
\hline Sucrose & 100 & 100 & 100 & 100 \\
\hline Corn starch & 530 & 530 & 530 & 530 \\
\hline $\mathrm{CLA}^{3}$ & - & - & 5 & 15 \\
\hline$\alpha$-Tocopherol acetate & 0.1 & 一 & - & - \\
\hline
\end{tabular}

${ }^{1}$ Casein, corn oil, vitamin mixture used were vitamin-E free type products.

${ }^{2}$ AIN-76 type mineral mixture, AIN-76 vitamin-E free vitamin mixture were used.

${ }^{3}$ CLA denotes conjugated linoleic acid.

acid composition of hepatic lipids. Moreover, there have been limited studies on the impact of CLA on endogenous antioxidant concentrations or activity in normal liver. Since vitamin E is the major chain breaking lipidsoluble antioxidant in tissues and plasma (11), the inclusion of vitamin $\mathrm{E}$ in the diet would have provided confusing results of CLA action in vivo with respect to oxidative stress. Therefore, we used a vitamin E-free diet as a control and compared the effect of CLA supplementation. The purpose of this study was to determine whether dietary CLA affects lipid peroxidation and the antioxidant activities, and can alter lipid composition in a manner which changes the oxidative stability.

\section{MATERIALS AND METHODS}

Materials. CLA was prepared from linoleic acid-rich safflower oil by alkali isomerization and concentrated by urea crystallization. The purity of CLA exceeded $95 \%$, and consisted of 2 major and several minor isomers. The two major isomers were cis 9,trans 11-CLA (42\%) and trans 10,cis 12-CLA (44\%). Vitamin E-free corn oil, vitamin-E free casein, vitamin-E free vitamin mixture and mineral mixture were purchased from Harlan Teklad Co. (Madison, WI, USA). (+) $\alpha$-Tocopherol acetate was obtained from Sigma Chemical Co. (St. Louis, USA) and all other chemicals were of analytical grade or purer.

Animals and diet. Five-week-old male Sprague-Dawley rats, purchased from Daehan Experimental Animal Inc. (Eumsung, Korea), were initially fed the chow diet for $7 \mathrm{~d}$. After acclimation, the rats (200-220 g) were assigned to four groups of ten rats each and individually housed with free access to water and diet during the entire experimental periods. The rats were fed experimental diets for $5 \mathrm{wk}$. The experimental diets were prepared according to the basal vitamin-E deficient diet containing $7 \%$ corn oil as shown in Table 1 . Corn oil, casein, and vitamin mixture were the vitamin-E free type. The normal diet was prepared by supplementing (+) $\alpha$-tocopherol acetate into the vitamin-E deficient control diet $(0.01 \% \mathrm{w} / \mathrm{w})$. CLA experimental diets were made by substituting CLA for corn oil at the level of $0.5 \%$ and $1.5 \%$, respectively. Rats were maintained at $23 \pm 2{ }^{\circ} \mathrm{C}$ temperature, $55 \pm 5 \%$ humidity with $12 \mathrm{~h}$ light:dark-cycle (light time, 06:30-18:30) and body weights were recorded weekly. All animal procedures were conducted in accordance with the Guideline for Animal Experimentation of the Korea Food Research Institute.

Sample preparation. The rats were sacrificed under ether anesthesia after $12 \mathrm{~h}$ fasting. The liver, kidneys, and spleen were excised, weighed and frozen immediately. An aliquot of each liver was removed and was stored at $-70^{\circ} \mathrm{C}$ for thiobarbituric acid reactive substance (TBARS) measurement and enzyme assay. Blood from the abdominal aorta was collected in a heparinized tube and centrifuged at $1,500 \times g$ for $20 \mathrm{~min}$ to separate the plasma. Plasma for high density lipoprotein-cholesterol (HDL-C) analysis was obtained by precipitating non-HDL with phosphotungstate followed by centrifugation (12). Liver microsomes were isolated by differential fractionation. Each liver was homogenized in 10 vol. of $50 \mathrm{~mm}$ phosphate buffer $(\mathrm{pH} \mathrm{7.0)}$ with Teflon-Elvehjem homogenizer and centrifuged at $10,000 \times g$ at $4^{\circ} \mathrm{C}$ for $20 \mathrm{~min}$ to obtain postmitochondrial supernatant, followed by recentrifugation of the supernatant at $105,000 \times g$ at $4^{\circ} \mathrm{C}$ for $1 \mathrm{~h}$. The resulting pellet was considered the microsome and resuspended in cold storage buffer (homogenizing buffer/ glycerol, 80:20). The entire fractionation procedure was conducted at $0-4^{\circ} \mathrm{C}$.

Lipid analyses. Triacylglycerol, total cholesterol, phospholipid, and HDL-cholesterol levels in plasma were measured using commercial enzymatic kits (Eiken, Japan). To analyze the fatty acid composition of the plasma and hepatic microsomal fraction, lipid extraction and transesterification were carried out simultaneously by the method described by Lepage and Roy (13). Fatty acid methyl esters were measured by gas chromatography (Hewlett-Packard 5890 Series) using an EC wax-packed capillary column (EC-1 $0.32 \mathrm{~mm}$ $\times 30 \mathrm{~m}$ ) equipped with an HP GC ChemStation data 
Table 2. Effect of CLA on body and organ weights in rats.

\begin{tabular}{llccc}
\hline \multicolumn{1}{c}{ Parameters } & Normal & Control & $0.5 \%$ CLA & $1.5 \%$ CLA \\
\hline Final body weight $(\mathrm{g})$ & $347 \pm 40.5^{\mathrm{ab}}$ & $366 \pm 24.9^{\mathrm{a}}$ & $312 \pm 24.2^{\mathrm{c}}$ & $320 \pm 37.6^{\mathrm{bc}}$ \\
Food efficiency ratio & $0.18 \pm 0.01^{\mathrm{a}}$ & $0.17 \pm 0.01^{\mathrm{a}}$ & $0.13 \pm 0.01^{\mathrm{b}}$ & $0.13 \pm 0.01^{\mathrm{b}}$ \\
Liver weight $(\mathrm{g})_{\text {Relative liver weight }^{1}(\%)}$ & $2.19 \pm 1.89^{\mathrm{b}}$ & $8.43 \pm 0.81^{\mathrm{b}}$ & $11.9 \pm 1.98^{\mathrm{a}}$ & $9.26 \pm 1.64^{\mathrm{b}}$ \\
Kidneys weight (g) $_{\text {Spleen weight }(\mathrm{g})}^{2.28 \pm 0.26^{\mathrm{c}}}$ & $2.30 \pm 0.14^{\mathrm{c}}$ & $3.86 \pm 0.81^{\mathrm{a}}$ & $2.83 \pm 0.37^{\mathrm{b}}$ \\
& $2.03 \pm 0.30^{\mathrm{a}}$ & $2.21 \pm 0.25^{\mathrm{a}}$ & $2.24 \pm 0.31^{\mathrm{a}}$ & $2.18 \pm 0.31^{\mathrm{a}}$ \\
\hline
\end{tabular}

Values are mean $\pm S D$ for 10 rats, and the means with the same roman superscripts $(a, b$, and c) in a row were not significantly different at $p<0.05$ by Duncan's multiple range test.

${ }^{1}$ Relative liver weight $=($ liver weight $) /($ body weight $) \times 100$. Rats were fed each of the experimental diets for $5 \mathrm{wk}$.

Normal, vitamin E-free diet with $\alpha$-tocopherol acetate; Control, vitamin E-free diet without $\alpha$-tocopherol acetate; $0.5 \%$ CLA, vitamin E-free diet with 0.5\% CLA substituted for corn oil; 1.5\% CLA, vitamin E-free diet with 1.5\% CLA substituted for corn oil.

Table 3. Effect of CLA on plasma lipid profiles and the activity of aspartate transaminase (AST) and alanine transaminase (ALT) in rats.

\begin{tabular}{ccccc}
\hline & Normal & Control & $0.5 \%$ CLA & $1.5 \%$ CLA \\
\hline Plasma lipid (mmol/L) & & & & \\
Triacylglycerol & $1.09 \pm 0.02^{\mathrm{a}}$ & $1.13 \pm 0.05^{\mathrm{a}}$ & $1.03 \pm 0.04^{\mathrm{ab}}$ & $0.90 \pm 0.03^{\mathrm{b}}$ \\
Total cholesterol & $2.20 \pm 0.09^{\mathrm{ab}}$ & $2.39 \pm 0.08^{\mathrm{a}}$ & $2.28 \pm 0.12^{\mathrm{a}}$ & $1.93 \pm 0.09^{\mathrm{b}}$ \\
HDL-cholesterol & $1.52 \pm 0.07$ & $1.56 \pm 0.06$ & $1.58 \pm 0.09$ & $1.36 \pm 0.07$ \\
Phospholipid & $2.54 \pm 0.11$ & $2.32 \pm 0.07$ & $2.30 \pm 0.09$ & $2.37 \pm 0.09$ \\
AST (unit/mL) & $50.7 \pm 1.20^{\mathrm{b}}$ & $63.5 \pm 0.89^{\mathrm{a}}$ & $42.2 \pm 2.32^{\mathrm{c}}$ & $33.3 \pm 1.39^{\mathrm{d}}$ \\
ALT (unit/mL) & $32.6 \pm 1.56^{\mathrm{b}}$ & $37.7 \pm 1.59^{\mathrm{a}}$ & $37.6 \pm 1.69^{\mathrm{a}}$ & $36.5 \pm 1.54^{\mathrm{ab}}$ \\
\hline
\end{tabular}

Values are mean $\pm S D$ for 10 rats, and the means with the same roman superscripts (a, b, c, and d) in a row were not significantly different at $p<0.05$ by Duncan's multiple range test. For dietary groups, see Table 2.

system, and a flame ionization detector. The fatty acids were identified by comparison of retention time of standard esters under the same conditions. Percentage of each fatty acid was calculated by normalization of the total fatty acid ethyl esters.

Enzyme assay and measurement of lipid peroxide content. The activities of aspartate transaminase (AST) and alanine transaminase (ALT) in plasma were assayed by enzymatic kits (Sinyang Chemical Co., Korea). Catalase activity was determined in liver homogenate at $25^{\circ} \mathrm{C}$ using hydrogen peroxide as substrate according to the method of Aebi (14). Total superoxide dismutase (SOD) activity was determined using the postmitochondrial fraction according to the method of Marklund and Marklund (15) with pyrogallol as the substrate. One unit of SOD activity is defined as the amount of enzyme required to inhibit the autoxidation of pyrogallol by $50 \%$. Glutathione peroxidase (GSH-Px) activity was measured in liver microsome with cumene hydroperoxide by the method of Lawrence and Burk (16). The protein concentration was measured by the method of Lowry et al. (17), with bovine serum albumin as the standard. Serum lipid peroxide content was assayed by the method of Yagi (18). About $1 \mathrm{~g}$ of each liver was homogenized in 5 vol. of $1.15 \% \mathrm{KCl}$ solution with a Teflon-Elvehjem homogenizer and centrifuged at $600 \times g$ for $10 \mathrm{~min}$ to obtain postnuclear supernatant. The supernatant was used to determine hepatic lipid peroxide content. Lipid peroxidation in liver was determined by the production of TBARS according to the method of Ohkawa et al. (19). Malondialdehyde, which has been identified as the product of lipid peroxidation, reacted with thiobarbituric acid and the absorbance was determined at $532 \mathrm{~nm}$.

Statistical analysis. All statistical analyses were carried out using ANOVA and Duncan's multiple range test; a $p$ value of $<0.05$ was selected as the limit of statistical significance. The statistical program used was SAS package (Cary, NC, USA).

\section{RESULTS}

\section{Diet consumption, growth, and tissue weight}

There were no significant differences in the diet intakes among the experimental groups. However, final body weight and food efficiency ratio were lower in CLA groups than in the control group (Table 2). In contrast, the CLA diets caused the increase of liver weight without any differences in the weights of other organs. A significant hepatomegaly was observed in the CLA groups as indicated by the relative liver weight to body weight.

Lipid parameters in plasma and the activities of AST and ALT

The effects of dietary CLA on plasma lipid level are summarized in Table 3. The concentrations of triacylglycerol and total cholesterol were affected by dietary 
Table 4. Fatty acid composition of plasma.

\begin{tabular}{lcccc}
\hline Fatty acids & Normal & Control & $0.5 \%$ CLA & $1.5 \%$ CLA \\
\hline C14:0 & $0.42 \pm 0.06^{\mathrm{a}}$ & $0.48 \pm 0.03^{\mathrm{a}}$ & $0.48 \pm 0.07^{\mathrm{a}}$ & $0.57 \pm 0.04^{\mathrm{a}}$ \\
$\mathrm{C} 16: 0$ & $24.1 \pm 0.40^{\mathrm{b}}$ & $24.2 \pm 0.63^{\mathrm{b}}$ & $27.3 \pm 0.31^{\mathrm{a}}$ & $26.9 \pm 0.30^{\mathrm{a}}$ \\
$\mathrm{C} 16: 1$ & $1.10 \pm 0.12^{\mathrm{b}}$ & $1.22 \pm 0.16^{\mathrm{ab}}$ & $1.77 \pm 0.27^{\mathrm{a}}$ & $1.62 \pm 0.21^{\mathrm{ab}}$ \\
$\mathrm{C} 18: 0$ & $10.4 \pm 0.40^{\mathrm{bc}}$ & $11.0 \pm 0.32^{\mathrm{ab}}$ & $9.65 \pm 0.41^{\mathrm{c}}$ & $11.9 \pm 0.25^{\mathrm{a}}$ \\
$\mathrm{C} 18: 1$ & $12.8 \pm 0.33^{\mathrm{c}}$ & $11.3 \pm 0.34^{\mathrm{c}}$ & $26.9 \pm 1.76^{\mathrm{a}}$ & $22.3 \pm 0.97^{\mathrm{b}}$ \\
$\mathrm{C} 18: 2$ & $27.2 \pm 0.34^{\mathrm{a}}$ & $24.5 \pm 0.73^{\mathrm{b}}$ & $14.8 \pm 0.87^{\mathrm{c}}$ & $16.4 \pm 0.66^{\mathrm{c}}$ \\
CLA & $\mathrm{ND}$ & $\mathrm{ND}$ & $\mathrm{ND}$ & $2.26 \pm 0.15$ \\
C18:3 & $0.54 \pm 0.13^{\mathrm{a}}$ & $0.57 \pm 0.10^{\mathrm{a}}$ & $0.26 \pm 0.07^{\mathrm{a}}$ & $0.27 \pm 0.09^{\mathrm{a}}$ \\
C20:3 & $0.45 \pm 0.19^{\mathrm{b}}$ & $0.18 \pm 0.05^{\mathrm{b}}$ & $1.64 \pm 0.15^{\mathrm{a}}$ & $1.46 \pm 0.19^{\mathrm{a}}$ \\
C20:4 & $21.7 \pm 1.02^{\mathrm{b}}$ & $24.7 \pm 1.13^{\mathrm{a}}$ & $16.4 \pm 1.28^{\mathrm{c}}$ & $14.8 \pm 0.93^{\mathrm{c}}$ \\
C22:5 & $0.11 \pm 0.07^{\mathrm{b}}$ & $0.38 \pm 0.13^{\mathrm{a}}$ & $\mathrm{ND}$ & $0.09 \pm 0.07^{\mathrm{b}}$ \\
C22:6 & $1.18 \pm 0.04^{\mathrm{a}}$ & $1.39 \pm 0.06^{\mathrm{a}}$ & $0.88 \pm 0.13^{\mathrm{b}}$ & $1.39 \pm 0.09^{\mathrm{a}}$ \\
SFA & $34.9 \pm 0.32^{\mathrm{d}}$ & $35.7 \pm 0.59^{\mathrm{c}}$ & $37.4 \pm 0.31^{\mathrm{b}}$ & $39.4 \pm 0.22^{\mathrm{a}}$ \\
MUFA & $13.9 \pm 0.38^{\mathrm{c}}$ & $12.5 \pm 0.45^{\mathrm{c}}$ & $28.7 \pm 1.94^{\mathrm{a}}$ & $23.9 \pm 1.09^{\mathrm{b}}$ \\
PUFA & $51.2 \pm 0.97^{\mathrm{a}}$ & $51.8 \pm 0.75^{\mathrm{a}}$ & $34.0 \pm 1.79^{\mathrm{b}}$ & $36.7 \pm 1.09^{\mathrm{b}}$ \\
\hline
\end{tabular}

Values are mean \pm SD for 10 rats, and the means with the same roman superscripts (a, b, c, and d) in a row were not significantly different at $p<0.05$ by Duncan's multiple range test.

SFA, saturated fatty acids; MUFA, monounsaturated fatty acids; PUFA, polyunsaturated fatty acids; ND, not detected. For dietary groups, see Table 2.

Table 5. Fatty acid composition of hepatic microsomal fraction.

\begin{tabular}{lcccc}
\hline Fatty acids & Normal & Control & $0.5 \%$ CLA & $1.5 \%$ CLA \\
\hline C14:0 & $0.22 \pm 0.02^{\mathrm{ab}}$ & $0.22 \pm 0.02^{\mathrm{ab}}$ & $0.16 \pm 0.02^{\mathrm{b}}$ & $0.23 \pm 0.02^{\mathrm{a}}$ \\
$\mathrm{C} 16: 0$ & $19.6 \pm 0.42^{\mathrm{c}}$ & $20.1 \pm 0.20^{\mathrm{bc}}$ & $21.6 \pm 0.41^{\mathrm{a}}$ & $21.0 \pm 0.51^{\mathrm{ab}}$ \\
$\mathrm{C} 16: 1$ & $0.77 \pm 0.14^{\mathrm{a}}$ & $0.78 \pm 0.09^{\mathrm{a}}$ & $1.02 \pm 0.17^{\mathrm{a}}$ & $1.04 \pm 0.17^{\mathrm{a}}$ \\
$\mathrm{C} 18: 0$ & $15.9 \pm 0.42^{\mathrm{c}}$ & $17.2 \pm 0.37^{\mathrm{c}}$ & $18.9 \pm 0.64^{\mathrm{b}}$ & $20.7 \pm 0.54^{\mathrm{a}}$ \\
$\mathrm{C} 18: 1$ & $12.4 \pm 0.99^{\mathrm{b}}$ & $11.7 \pm 0.67^{\mathrm{b}}$ & $17.1 \pm 1.19^{\mathrm{a}}$ & $15.5 \pm 0.86^{\mathrm{a}}$ \\
C18:2 & $24.4 \pm 0.65^{\mathrm{a}}$ & $21.5 \pm 0.63^{\mathrm{b}}$ & $10.9 \pm 0.70^{\mathrm{c}}$ & $12.5 \pm 0.64^{\mathrm{c}}$ \\
CLA & ND & $\mathrm{ND}$ & $0.32 \pm 0.04^{\mathrm{b}}$ & $2.35 \pm 0.38^{\mathrm{a}}$ \\
C18:3 & $0.70 \pm 0.05^{\mathrm{a}}$ & $0.62 \pm 0.06^{\mathrm{a}}$ & $0.25 \pm 0.02^{\mathrm{b}}$ & $0.35 \pm 0.05^{\mathrm{b}}$ \\
C20:3 & $0.85 \pm 0.05^{\mathrm{b}}$ & $0.74 \pm 0.04^{\mathrm{b}}$ & $2.70 \pm 0.23^{\mathrm{a}}$ & $2.33 \pm 0.25^{\mathrm{a}}$ \\
C20:4 & $20.3 \pm 0.91^{\mathrm{ab}}$ & $21.7 \pm 0.66^{\mathrm{a}}$ & $21.9 \pm 0.82^{\mathrm{a}}$ & $18.1 \pm 0.72^{\mathrm{b}}$ \\
C22:4 & $0.65 \pm 0.05^{\mathrm{a}}$ & $0.60 \pm 0.05^{\mathrm{a}}$ & $0.33 \pm 0.02^{\mathrm{b}}$ & $0.27 \pm 0.02^{\mathrm{b}}$ \\
C22:5 & $1.09 \pm 0.13^{\mathrm{a}}$ & $1.37 \pm 0.19^{\mathrm{a}}$ & $1.29 \pm 0.13^{\mathrm{a}}$ & $1.09 \pm 0.07^{\mathrm{a}}$ \\
C22:6 & $3.01 \pm 0.19^{\mathrm{c}}$ & $3.58 \pm 0.09^{\mathrm{b}}$ & $3.49 \pm 0.18^{\mathrm{bc}}$ & $4.57 \pm 0.22^{\mathrm{a}}$ \\
SFA & $35.8 \pm 0.48^{\mathrm{d}}$ & $37.5 \pm 0.33^{\mathrm{c}}$ & $40.6 \pm 0.53^{\mathrm{b}}$ & $42.2 \pm 0.33^{\mathrm{a}}$ \\
MUFA & $13.2 \pm 1.07^{\mathrm{b}}$ & $12.5 \pm 0.72^{\mathrm{b}}$ & $18.1 \pm 1.31^{\mathrm{a}}$ & $16.6 \pm 1.03^{\mathrm{a}}$ \\
PUFA & $53.0 \pm 0.90^{\mathrm{a}}$ & $50.1 \pm 0.82^{\mathrm{b}}$ & $39.1 \pm 1.12^{\mathrm{c}}$ & $40.7 \pm 0.96^{\mathrm{c}}$
\end{tabular}

Values are mean $\pm S D$ for 10 rats, and the means with the same roman superscripts (a, b, c, and d) in a row were not significantly different at $p<0.05$ by Duncan's multiple range test.

SFA, saturated fatty acids; MUFA, monounsaturated fatty acids; PUFA, polyunsaturated fatty acids; ND, not detected. For dietary groups, see Table 2 .

treatments, in contrast to the absence of differences in HDL-cholesterol and phospholipid. The CLA diets tended to lower triacylglycerol and total cholesterol levels compared with the vitamin-E free control diet, and the reduction was statistically significant at the level of $1.5 \mathrm{wt} \%$.

The activities of AST and ALT are also represented in Table 3, as biochemical parameters of damage in liver function. The vitamin E-free control group had significantly higher activities compared with the normal basal group. The CLA diets lowered the activities of AST and ALT, although the decrease in ALT was not statisti- cally significant. The reduction of AST activity was remarkable.

Fatty acid composition of plasma and hepatic microsome

The fatty acid composition of the plasma and hepatic microsomal fraction are shown in Tables 4 and 5 as the percentage of total fatty acids. Dietary CLA was incorporated into the plasma and hepatic microsome, especially dose-dependently in the hepatic microsomal fraction. The CLA diets affect the composition of other major fatty acids, in contrast to the similar composition between normal basal diet-fed group and vitamin E-free control diet-fed group. In the CLA-fed groups, linoleic 

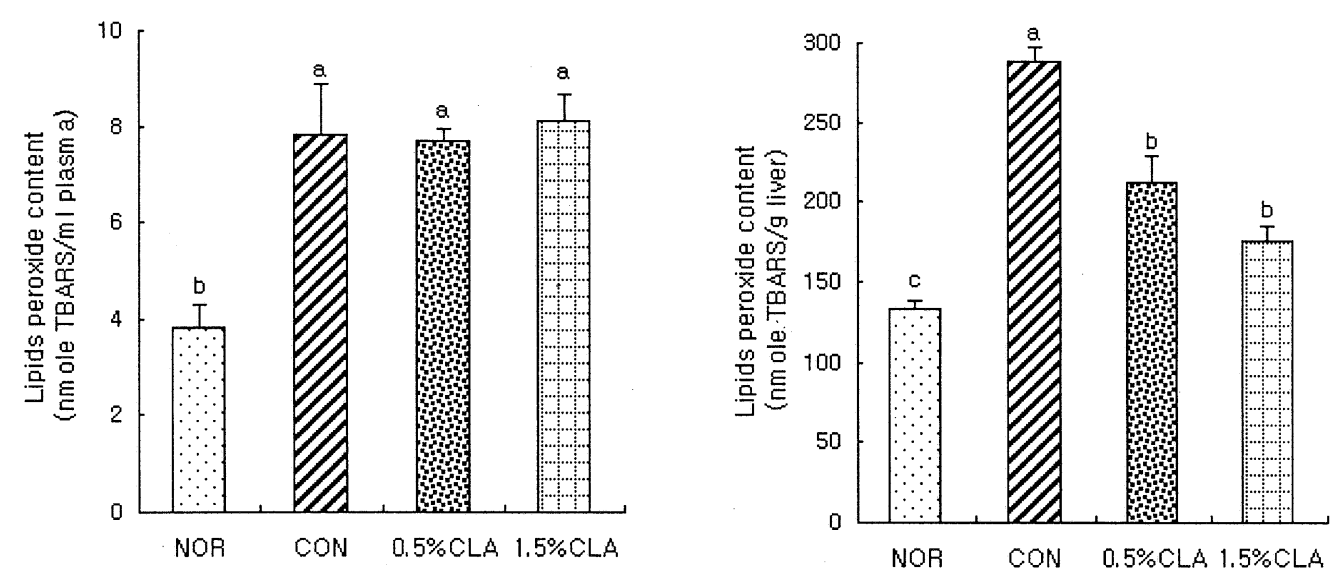

Fig. 1 Effect of CLA on plasma and hepatic thiobarbituric acid reactive substance (TBARS) contents in rats. Values are mean \pm SD for 10 rats, and the means with the same roman superscripts (a and b) were not significantly different at $p<0.05$ by Duncan's multiple range test. Nor, vitamin E-free diet with $\alpha$-tocopherol acetate; Con, vitamin E-free diet without $\alpha$-tocopherol acetate; $0.5 \%$ CLA, vitamin E-free diet with $0.5 \%$ CLA substituted for corn oil; $1.5 \%$ CLA, vitamin E-free diet with $1.5 \%$ CLA substituted for corn oil.

Table 6. Effect of CLA on the activities of antioxidative enzyme in liver.

\begin{tabular}{|c|c|c|c|c|}
\hline & Normal & Control & $0.5 \%$ CLA & $1.5 \%$ CLA \\
\hline $\begin{array}{l}\text { SOD } \\
\text { (unit/mg protein) }\end{array}$ & $7.5 \pm 0.35^{b}$ & $9.3 \pm 0.20^{\mathrm{a}}$ & $7.9 \pm 0.22^{b}$ & $7.8 \pm 0.27^{b}$ \\
\hline $\begin{array}{l}\text { Catalase } \\
\text { (umol } \mathrm{H}_{2} \mathrm{O}_{2} / \mathrm{min} / \mathrm{mg} \text { protein) }\end{array}$ & $189 \pm 4.0$ & $184 \pm 4.1$ & $183 \pm 3.0$ & $187 \pm 8.1$ \\
\hline $\begin{array}{l}\text { GSH-Px } \\
\text { (nmol NADPH/min/mg protein) }\end{array}$ & $299 \pm 11.4^{\mathrm{a}}$ & $216 \pm 13.6^{c}$ & $255 \pm 8.5^{\mathrm{b}}$ & $266 \pm 9.5^{b}$ \\
\hline
\end{tabular}

Values are mean \pm SD for 10 rats, and the means with the same roman superscripts ( $a$ and $b$ ) in a row were not significantly different at $p<0.05$ by Duncan's multiple range test.

For dietary groups, see Table 2.

and arachidonic acids were decreased while oleic acid was increased in both plasma and hepatic microsome. In addition, total content of polyunsaturated fatty acids was significantly reduced but those of saturated and monounsaturated fatty acids were elevated in both plasma and hepatic microsome.

Lipid peroxidation and the activities of antioxidant enzymes

Concentrations of plasma and hepatic TBARS, as an estimate of lipid peroxidation, are shown in Fig. 1. When compared with the normal basal diet, the vitamin E-free control diet resulted in an elevated TBARS level. However, the CLA diets lowered the hepatic TBARS level significantly, even though it could not reach the level of the normal basal group. Plasma TBARS levels were comparable among the vitamin Efree experimental groups. The activities of antioxidant enzymes in hepatic tissue are represented in Table 6. SOD activity was significantly greater in rats fed the vitamin E-free control diet, which was restored to the normal basal level by feeding of CLA. GSH-Px activity was low in vitamin E-free diet-fed rats, compared with the rats fed the normal basal diet. The CLA diet increased the activity of GSH-Px, even though it could not reach the level of the normal basal group. The catalase activity did not show any difference among the experimental groups.

\section{DISCUSSION}

The reduction of body weight gain by dietary supplementation of CLA is well consistent with the other animal model studies (20-22). However, the effect of CLA on body weight was not dose-dependent in our study. Previous studies illustrate that the reduction in body weight gain depends on the amount and isomer composition of the CLA mixture, treatment duration, body weights and energy intakes of the subject (23). The reduction in body weight gain is due to the action of the single isomer t10,c12-CLA (20). One study demonstrated that greater weight reductions by CLA were achieved in male AKR/J mice fed a high-fat (45\% of calories) diet compared with the low-fat (15\% of calories) diet (21). In addition, a dose-response effect was observed when the animals were given a high-fat diet supplemented with $0.25-1.0 \%$ CLA (24). Therefore, the absence of dose-dependent weight reduction effect in our study could be ascribed to the low fat content of experimental diet (14\% of calories) and dosage of CLA.

Another consequence of dietary CLA supplementation was massive liver enlargement accompanying an increase in liver cholesterol and triacylglycerol content. 
The hepatomegaly and concomitant enlargement of spleen was also observed in other studies and have raised safety issues. The tissue examination did not show any severe pathologic changes but increased lipid droplets in the liver and spleen (24-26). However, the cellular and molecular mechanism involved in this process are not well known. It has been suggested that fatty liver could be a consequence of the increased lipogenesis in the liver in compensating for the reduction of fat deposition in the adipose tissue $(25,27)$.

Numerous studies have documented that CLA has antiatherogenic activity in human and experimental animal $(2,5,28)$ by decreasing plasma lipid levels. Consistent with these findings, the present study demonstrates that CLA at $1.5 \mathrm{wt} \%$ significantly reduced the level of total cholesterol and triacylglycerol. It has been demonstrated that free radical-mediated oxidative stress implicated the genesis and progression of atherosclerosis (29). The stress results from the imbalance between the production of free radicals and effectiveness of the antioxidant defense system. The activity of free radicals is countered by a system of antioxidant defenses. Therefore, the antioxidant activity of CLA has been investigated as a possible mechanism by several research groups but they reported conflicting results (6-8). Most studies were conducted in vitro and used a defined carcinogenic model system. However, there has been limited information about the effect of CLA on lipid peroxidation in normal liver tissue, even though PUFA taken into the body was mostly delivered to liver cells and liver is one of the principal targets of PUFA peroxidative effects (30). Our major concern was whether CLA acts in a protective role against oxidative damage in hepatic tissue, with respect to antiatherosclerosis. Among the experimental oxidative stress models, vitamin E-deficient diets have been well investigated in animals. In these animals, there is a deficiency of vitamin $\mathrm{E}$ in the cell membrane and decreased antioxidative status in the lipid bilayers, and severe membrane damage occurs (31). We used a vitamin E-free diet to induce peroxidative damage as a control and compared the effect of CLA supplementation.

In our study, the concentration of plasma and hepatic TBARS was increased in the vitamin E-free control diet group compared to the vitamin E-supplemented normal group, which indicates the stimulation of tissue lipid peroxidation due to oxidative stress. In contrast, TBARS production was reduced by the intake of CLA in a dosedependent manner in hepatic microsome, whereas it had no effect in the concentration of plasma TBARS. The CLA concentration in the plasma and hepatic microsome fraction suggests that CLA was absorbed and distributed to the liver more than plasma. However, further investigation is required to determine why TBARS in plasma does not respond to a high dose of dietary CLA.

In addition, dietary CLA protected liver tissue from peroxidative damage, which is supported by the assay of enzymes related to the liver disease. Feeding of the vitamin E-free control diet increased the activities of AST and ALT: This result may be related to the increase of lipid peroxidation in liver tissue by oxidative stress. The reduction of AST by CLA indicates that CLA alleviates the liver damage induced by oxidative stress.

The role of antioxidants and the antioxidant defense system such as superoxide dismutase (SOD), catalase, and glutathione peroxidase (GSH-Px) to protect against oxidative insults is well characterized in the liver. In contrast to the absence of differences in the activity of catalase, SOD activity was elevated by the vitamin Efree control diet compared with the normal basal diet and recovered by CLA feeding. SOD is known to be the first line of antioxidant defense enzyme by scavenging superoxide radicals to hydrogen peroxide and water (32). The increase of SOD activity in the vitamin E-free control diet supports the contention that oxidative stress increases the activities of antioxidative enzymes (33). On the other hand, the recovery of SOD activity suggests a possibility that generation of superoxide radicals $\left(\mathrm{O}_{2}{ }^{-}\right)$, the major initiator of the oxygen radical cascade that feeds into the lipid peroxidation chain reaction, was reduced in the CLA-fed rats. Yu reported the free radical scavenging property of CLA against the stable 2,2,-diphenyl-1-picryhydrazyl radical (DPPH·) by electron spin resonance (ESR) spectrometry (34), which provides supportive evidence of the possible quenching effect of CLA on potential reactive oxygen species.

GSH-Px functions as a protection enzyme by converting peroxides into the corresponding alcohols (35). It is conceivable that low activity of GSH-Px may render the tissue more susceptible to lipid peroxidation damage (36). In accordance, we observed a significant decrease in the activity of GSH-Px in vitamin E-free diet-fed rats with the increase of TBARS level. The observation that CLA caused a significant increase in GSH-Px activity while having no significant effect on catalase activity may be supportive of an antioxidative effect of CLA in protecting against lipid peroxidation.

In addition to the antioxidant enzyme-sparing effect shown in our study, it does not exclude possible effects of CLA in maintaining levels of other antioxidants such as $\alpha$-tocopherol as reported previously (2). The apparent sensitivity of the antioxidant defense enzyme system to CLA coupled with the inhibitory effect of lipid peroxidation suggests that CLA has antioxidative properties in normal hepatic tissue.

Another interesting result was that dietary CLA modulated fatty acid composition, as well as incorporating into the plasma and hepatic lipids. In the CLA-fed group, significantly high content of oleic and stearic acids was detected with a concomitant decrease of linoleic and arachidonic acid. This result is highly consistent with many previous reports (37-39) even though slightly different results were reported (40). This suggests that the selection of the composition of CLA mixture, basal diet composition, organ and species as well might have a change in CLA effect on fatty acid composition. However, the changes in polyunsaturated fatty acid (PUFA) such as arachidonic acid observed in the previous reports and confirmed in the present study 
are of particular importance. Considering that the accumulation of PUFA such as arachidonic acid potentiates the susceptibility to peroxidation, it is noteworthy that CLA alters the fatty acid composition of biological tissue in a manner increasing oxidative stability. In addition, the decrease of arachidonic acid content suggests that the subsequent decreased synthesis of arachidonate-derived eicosanoid production may play a role in the antiatherogenic effect observed in CLA-fed rats.

In summary, we found that the ability of CLA to decrease polyenoic fatty acid concentration in both plasma and hepatic membrane, with the antioxidantsparing property, could decrease the formation of deleterious lipid peroxidation product in vitamin E-deficient rats.

\section{Acknowledgments}

This work was supported by a research grant (M10313120003-03B3412-00310) from the Ministry of Science \& Technology of Korea.

\section{REFERENCES}

1) Ip C. 1997. Review of the effects of trans fatty acids, oleic, $n-3$ polyunsaturated fatty acids and conjugated linoleic acid on mammary carcinogenesis in animals. Am J Clin Nutr 66: 1523S-1529S.

2) Nicolosi RJ, Rogers EJ, Kritchevsky D, Scimeca JA, Huth PJ. 1997. Dietary conjugated linoleic acid reduces plasma lipoproteins and early aortic atherosclerosis in hypercholesterolemic hamsters. Artery 22: 266-277.

3) Miller CC, Park Y, Pariza MW, Cook ME. 1994. Feeding conjugated linoleic acid to animals partially overcomes catabolic response due to endotoxin injection. Biochem Biophys Res Commun 198: 1107-1112.

4) West DB, Delany JP, Camet PM, Blihm F, Truett AA. 1998. Effects of conjugated linoleic acid on body fat and energy metabolism in the mouse. Am J Physiol 275: R667-R672.

5) Lee KN, Kritchevsky D, Pariza MW. 1994. Conjugated linoleic acid and atherosclerosis in rabbits. Atherosclerosis 108: 19-25.

6) Ip C, Chin SF, Scimeca JA, Pariza MW. 1991. Mammary cancer prevention by conjugated dienoic derivative of linoleic acid. Cancer Res 51: 6118-6124.

7) Ha YL, Storkson J, Pariza MW. 1990. Inhibtion of benzo[a]pyrene-induced mouse forestomach neoplasia by conjugated dienoic derivatives of linoleic acid. Cancer Res 50: 1097-1101.

8) van den Berg JJ, Cook NE, Tribble D. 1995. Reinvestigation of the antioxidant properties of conjugated linoleic acid. Lipids 30: 599-605.

9) Bretillion L, Chardigny J, Gregoire S, Berdeaux O, Sebedio J. 1999. Effect of conjugated linoleic acid isomers on the hepatic microsomal desaturation activities in vitro. Lipids 34: 965-969.

10) Huang YS, Nassar BA. 1990. Modulation of tissue fatty acid composition, prostaglandin production and cholesterol levels by dietary manipulation of $n-3$ and $n-6$ essential fatty acid metabolites. In: Omega- 6 Essential Fatty Acids, Pathophysiology and Roles in Clinical Medicines (Horrobin DF, ed), p 127-144. Alan R Liss Inc., New York.

11) Burton GW, Traber MG. 1990. Vitamin E: antioxidant activity, biokinetics, and bioavailability. Ann Rev Nutr 10: 357-382.

12) Assman G, Schriewer H, Schmitz G, Hagel EO. 1983. Quantification of high density lipoprotein cholesterol by precipitation with phosphotungstic acid/ $\mathrm{MgCl}_{2}$. Clin Chem 29: 2026-2030.

13) Lepage G, Roy CC. 1986. Direct transesterification of all classes of lipids in a one-step reaction. J Lipid Res 27: 114-120.

14) Aebi H. 1984. Catalase in vitro. In: Methods in Enzymology (Packer L, ed), Vol 105, p 121-126. Academic Press, Orlando.

15) Marklund S, Marklund G. 1974. Involvement of the superoxide anion radical in the autoxidation of pyrogallol and a convenient assay for superoxide dismutase. Eur J Biochem 47: 469-474.

16) Lawrence RA, Burk RF. 1976. Glutathione peroxidase activity in selenium deficient rat liver. Biochem Biophys Res Commun 71: 952-958.

17) Lowry OH, Rosebrough NJ, Farr AL, Randall RT. 1951. Protein measurement with folin phenol reagent. J Biol Chem 193: 265-275.

18) Yagi K. 1976. Microdetermination of lipoperoxide in blood. Biochem Med 15: 212-216.

19) Ohkawa H, Ohishi N, Yagi K. 1979. Assay for lipid peroxides in animal tissues by thiobarbituric acid reactions. Anal Biochem 95: 351-358.

20) Park Y, Storkson JM, Albright KJ, Liu W, Pariza MW. 1999. Evidence that trans-10,cis-12 isomer of conjugated linoleic acid induces body composition changes in mice. Lipids 34: 235-241.

21) West DB, Delany JP, Camel PM, Blohm F, Truett AA, Scimeca J. 1998. Effects of conjugated linoleic acid on body fat and energy metabolism in the mouse. Am J Physiol 275: R667-672.

22) Terpstra AH, Beynen AC, Everts H, Kocsis S, Katan MB Zock PL. 2002. The decrease in body fat in mice fed conjugated linoleic acid is due to increase in energy expenditure and energy loss in the excreta. J Nutr 132: 940945.

23) Wang Y, Jones PJH. 2004. Dietary conjugated linoleic acid and body composition. Am J Clin Nutr 79: 1153S1158S.

24) Delany JP, Blohm F, Truett AA, Scimca JA, West DB. 1999. Conjugated linoleic acid rapidly reduces body fat content in mice without affecting energy intake. Am J Physiol 276: R1172-1179.

25) Takahashi Y, Kushiro M, Shinohara K, Ide T. 2003. Activity and mRNA levels of enzymes involved in hepatic fatty acid synthesis and oxidation in mice fed conjugated linoleic acid. Biochim Biophys Acta 1631: 265-273.

26) Clement L, Porier H, Niot I, Bocher V, Guerre-Millo M, Krief S, Staels B, Besnard P. 2002. Dietary trans-10,cis12 conjugated linoleic acid induces hyperinsulinemia and fatty liver in the mouse. J Lipid Res 43: 1400-1409.

27) Peters JM, Park Y, Gonzalez FJ, Pariza MW. 2001. Influence of conjugated linoleic acid on body composition and target gene expression in peroxisomeproliferatoractivated receptor alpha-null mice. Biochim Biophys Acta 1533: 233-242.

28) Mougios V, Matsakas A, Petridou A, Ring S, Sagredos A, Melissopoulou A, Tsigils N, Nikolaidis M. 2001. Effect of supplementation with conjugated linoleic acid on human serum lipids and body fat. J Nutr Biochem 12: 
585-594.

29) Prasad K, Kalra J. 1993. Oxygen free radicals and hypercholesterolemic atherosclerosis. Am Heart J 125: 958-971.

30) Nilsson A, Hjelte L, Strandvik B. 1992. Incorporation of dietary $\left[{ }^{14} \mathrm{C}\right]$ arachidonic acid and $\left[{ }^{3} \mathrm{H}\right]$ eicosapentaenoic acid into tissue lipids during absorption of a fish oil emulsion. J Lipid Res 33: 1295-1305.

31) Chow CK. 1992. Oxidative damage in the red cells of vitamin E-deficient rats. Free Radical Res Commun 16: 247-258.

32) Fridovich I. 1995. Superoxide radical and superoxide dismutase. Annu Rev Biochem 64: 97-112.

33) Ruiz-Gutiérrez V, Pérez-Espinosa A, Vázquez CM, SantaMaria C. 1999. Effect of dietary fats (fish, olive and high-oleic acid sunflower oils) on lipid composition and antioxidant enzymes in rat liver. Br J Nutr 82: 233241.

34) Yu L. 2001. Free radical scavenging properties of conjugated linoleic acids. J Agric Food Chem 49: 3452-3456.

35) Burk RF, Trumble MJ, Lawrence RA. 1980. Rat hepatic cytosolic glutathione-dependent enzyme protection against lipid peroxidation in the NADPH-microsomal lipid peroxidation system. Biochim Biophys Acta 619: 34-41.

36) Tsai AC, Thie GM, Lin CR. 1977. Effect of cholesterol feeding on tissue lipid peroxidation, glutathione peroxidase activity and liver microsomal functions in rat and guinea pigs. J Nutr 107: 310-319.

37) Belury MA, Kempa-Steczko A. 1997. Conjugated linoleic acid moduates hepatic lipid composition in mice. Lipids 32: 199-204.

38) Livisay SA, Zhou S, Ip C, Decker EA. 2000. Impact of dietary conjugated linoleic acid on the oxidative stability of rat liver microsomes and skeletal muscle homogenates. J Agric Food Chem 48: 4162-4167.

39) Joo S, Lee J, Ha Y, Park G. 2002. Effects of dietary conjugated linoleic acid on fatty acid composition, lipid oxidation, color, and water-holding capacity of pork loin. $J$ Anim Sci 80: 108-112.

40) Stangl GA. 2000. High dietary levels of a conjugated linoleic acid mixture alter hepatic glycerophospholipid class profile and cholesterol-carrying serum lipoproteins of rats. J Nutr Biochem 11: 184-191. 